\title{
A Systematic Review to Define the Speech and Language Benefit of Early ( $<12$ Months) Pediatric Cochlear Implantation
}

\author{
Hanneke Bruijnzeel ${ }^{a, b}$ Fuat Ziylan ${ }^{a}$ Inge Stegeman ${ }^{a, b}$ Vedat Topsakal ${ }^{a, b}$ \\ Wilko Grolman a, b \\ aDepartment of Otorhinolaryngology and Head and Neck Surgery, University Medical Center Utrecht, and \\ ${ }^{b}$ Brain Center Rudolf Magnus, Utrecht, The Netherlands
}

\section{Key Words}

Cochlea $\cdot$ Cochlear implantation · Cochlear implants . Hearing loss $\cdot$ Speech perception $\cdot$ Speech production measurement $\cdot$ Language tests

\begin{abstract}
Objective: This review aimed to evaluate the additional benefit of pediatric cochlear implantation before 12 months of age considering improved speech and language development and auditory performance. Materials and Methods: We conducted a search in PubMed, EMBASE and CINAHL databases and included studies comparing groups with different ages at implantation and assessing speech perception and speech production, receptive language and/or auditory performance. We included studies with a high directness of evidence (DoE). Results: We retrieved 3,360 articles. Ten studies with a high DoE were included. Four articles with medium DoE were discussed in addition. Six studies compared infants implanted before 12 months with children implanted between 12 and 24 months. Follow-up ranged from 6 months to 9 years. Cochlear implantation before the age of 2 years is beneficial according to one speech perception score (phonetically balanced kindergarten combined with consonantnucleus-consonant) but not on Glendonald auditory screening procedure scores. Implantation before 12 months result-
\end{abstract}

ed in better speech production (diagnostic evaluation of articulation and phonology and infant-toddler meaningful auditory integration scale), auditory performance (Categories of Auditory Performance-II score) and receptive language scores (2 out of 5; Preschool Language Scale combined with oral and written language skills and Peabody Picture Vocabulary Test). Conclusions: The current best evidence lacks level 1 evidence studies and consists mainly of cohort studies with a moderate to high risk of bias. Included studies showed consistent evidence that cochlear implantation should be performed early in life, but evidence is inconsistent on all speech and language outcome measures regarding the additional benefit of implantation before the age of 12 months. Long-term follow-up studies are necessary to provide insight on additional benefits of early pediatric cochlear implantation.

(C) 2016 The Author(s)

Published by S. Karger AG, Basel

\section{Introduction}

Through the introduction of universal newborn hearing screening, infants with profound sensorineural hearing loss are recognized earlier after birth. This has led to earlier cochlear implantation (CI) in congenitally deaf children [Lammers et al., 2015]. In 1990, the Food and

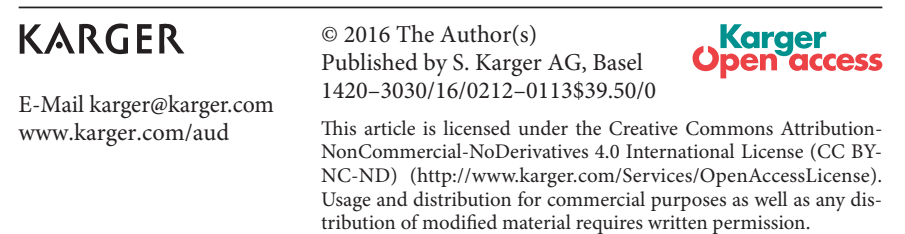

Hanneke Bruijnzeel

Department of Otolaryngology and Head and Neck Surgery

Utrecht Medical Center, Heidelberglaan 100

NL-3584 CX Utrecht (The Netherlands)

E-Mail ent-research@ umcutrecht.nl tribution of modified material requires written permission. 
Drug Administration (FDA) approved pediatric CI (PCI) from the age of 2 years [Clark, 2000], whereas currently the FDA has approved PCI in children from 12 months onwards [Bronstein, 2012].

Neuroplastic and neurolinguistic dynamics are the main reasons to opt for early CI, mainly to gain optimal benefit from implantation during the critical period of cortex neuroplasticity, a sensitive period in which speech and language are developed. In this critical period, auditory experience must occur to organize the neural connections in the brain. Human central auditory pathways are thought to be maximally plastic for a period of 3.5 years [Sharma et al., 2002, 2007]. CI outside this sensitive language period might result in the development of different and delayed patterns of speech and language. Because the period of neurolinguistic development is flexible and varies between children, determining the optimal timing for CI based on these time frames remains difficult and has not yet been strictly defined [Vlastarakos et al., 2010].

The 'earlier the better' trend [Leigh et al., 2013] in CI originated mainly from results and assumptions from both physiological studies and extrapolation of data of studies with children using hearing aids. Children fitted with hearing aids within the first 2 months of life were found to have significantly better language development than children aided between 3 and 12 months [Mah-rya and Yoshinaga-Itano, 1995], which suggested an indication to start implanting children earlier to accomplish optimal language development and minimize the period of auditory deprivation.

Some surgeons suggest that CI should be performed under the age of 1 year, or even before the age of 6 months [Colletti et al., 2005]. Despite the fact that early implantation is considered to be a predictor of good language and speech development, there is conflicting and incomplete evidence regarding the benefits of implantation under 12 months and particularly under 6 months [Tomblin et al., 2005; Leigh et al., 2013]. An underlying reason for this conflicting evidence could be that early implantation $(<9$ months) leads to the loss of the ability to discern: the accurate determination of hearing abilities, hearing aid benefit [Tomblin et al., 2005] and coexisting cognitive and behavioral anomalies, which could all affect the performance and outcome following CI.

We aim to identify the existing evidence of the additional benefit on speech and language development and auditory performance of PCI performed within the 1st year of life compared to implantation after 12 months of age.

\section{Materials and Methods}

\section{Literature Selection - Search Strategy}

To systematically identify all relevant studies regarding the influence of age at PCI, we performed a literature search in the following three databases: (1) PubMed, (2) EMBASE and (3) CINAHL (Cumulative Index to Nursing and Allied Health Literature) on April 24, 2014. Because search results can change over time, monthly search updates were checked for additional article inclusions. Up to date, this resulted in no additional article inclusion. We included studies focusing on the assessment of speech and language outcome after PCI by comparing groups of children implanted at different ages. We developed a search strategy by establishing a matrix of synonyms to cover all possible outcome measures of speech perception, speech production and language development following PCI (Appendix). The authors can be contacted to receive the review protocol. The search term 'age' (or related synonyms as 'below 1 year') was not included in the search strategy, because age was the principal prognostic factor in the current review.

\section{Study Selection}

Two authors (H.B. and I.S.) performed independent systematic title and abstract screening based on predefined selection criteria (fig. 1). Studies that included a comparison between different age groups at the time of PCI were included. Subsequently, the same authors screened the full text of the selected articles for eligibility. As 1999 was the year of FDA approval of implantation before the age of 2 years [Clark, 2000], we included studies published after this date to increase the likelihood to retrieve data for analysis on the study population of interest. Because it could take a significant amount of time before the benefits of early CI can be demonstrated [Beadle et al., 2005], we aimed to include studies with a minimal follow-up of 5 years. If several studies were retrieved that analyzed the same study cohort, the study with the largest sample size was included. Disagreement was solved by discussion between the two authors. No language restrictions were applied.

\section{Quality or Risk of Bias Assessment}

Two authors (H.B. and F.Z.) independently assessed the methodological quality of included studies. This assessment was performed using a constructed critical appraisal tool assessing both directness of evidence (DoE) and risk of bias (RoB) at both study level and outcome level, represented in 11 and 5 domains, respectively (table 1). Both main domains were graded per complete domain and rated as having a low, moderate or high DoE or RoB. Due to the fact that both long-term follow-up is important and speech/ language development should be assessed on various language domains, we selected studies with a high DoE. Consensus on quality assessment was reached by discussion between the authors (H.B. and F.Z.). Publication bias can mark results of PCI. To prevent selective reporting of identified evidence, we aimed to present results on all speech/language outcome assessments that were performed in each independent study.

\section{Data Extraction and Analysis}

The same authors (H.B. and F.Z.) collected the following information from studies: authors, publication year, study design and sample size (table 1). The first reviewer (H.B.) independently collected additional information of the included studies on: age group 


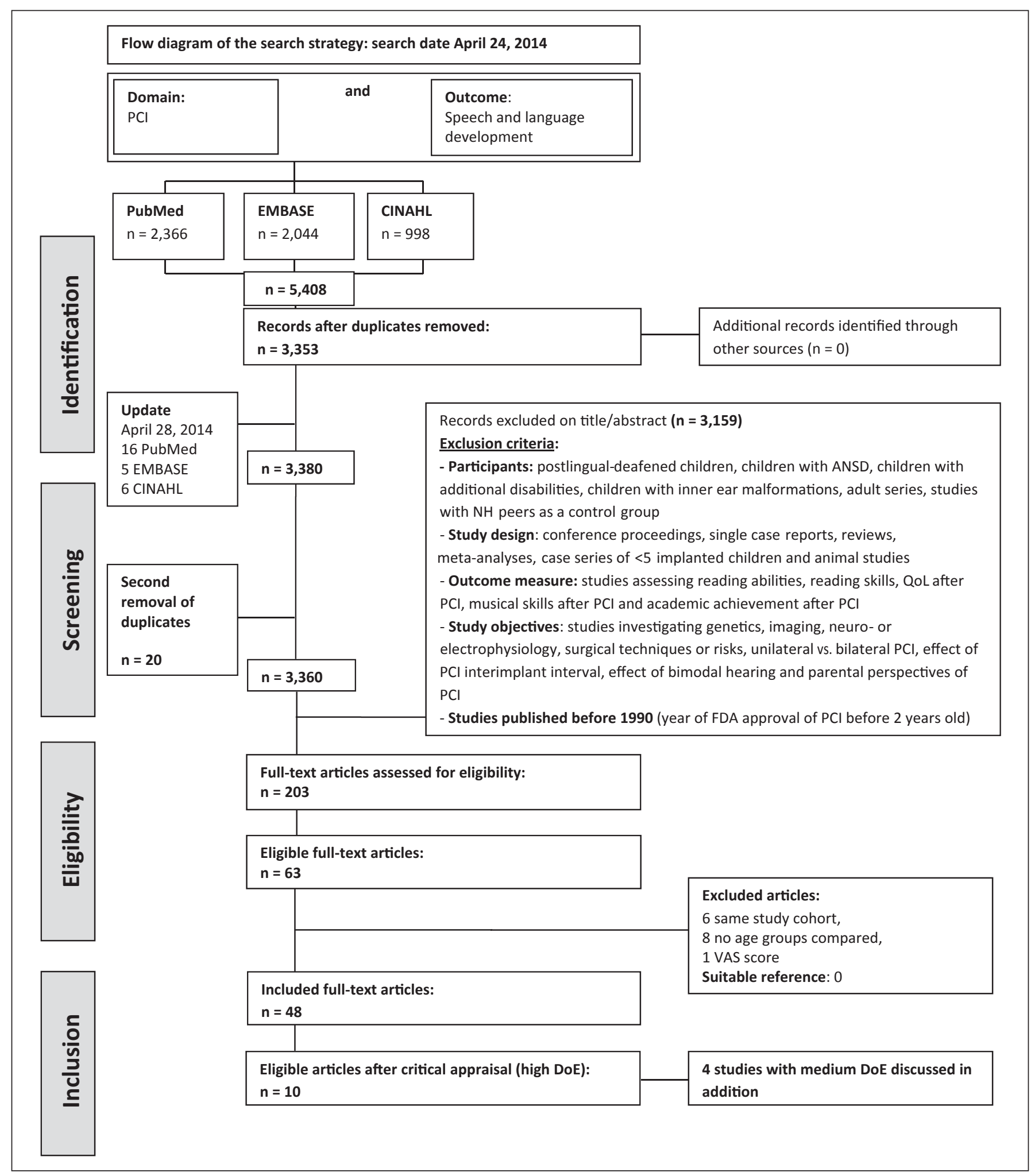

Fig. 1. Flow chart of the selection of studies assessing the influence of age at PCI on postoperative speech and language performance. $\mathrm{ANSD}=$ Auditory neuropathy spectrum disorder; DoE = directness of evidence; FDA = Food and Drug Administration; PCI = pediatric cochlear implantation; QoL = quality of life; VAS = visual analogue scale.

Is There a Speech and Language Developmental Benefit? 


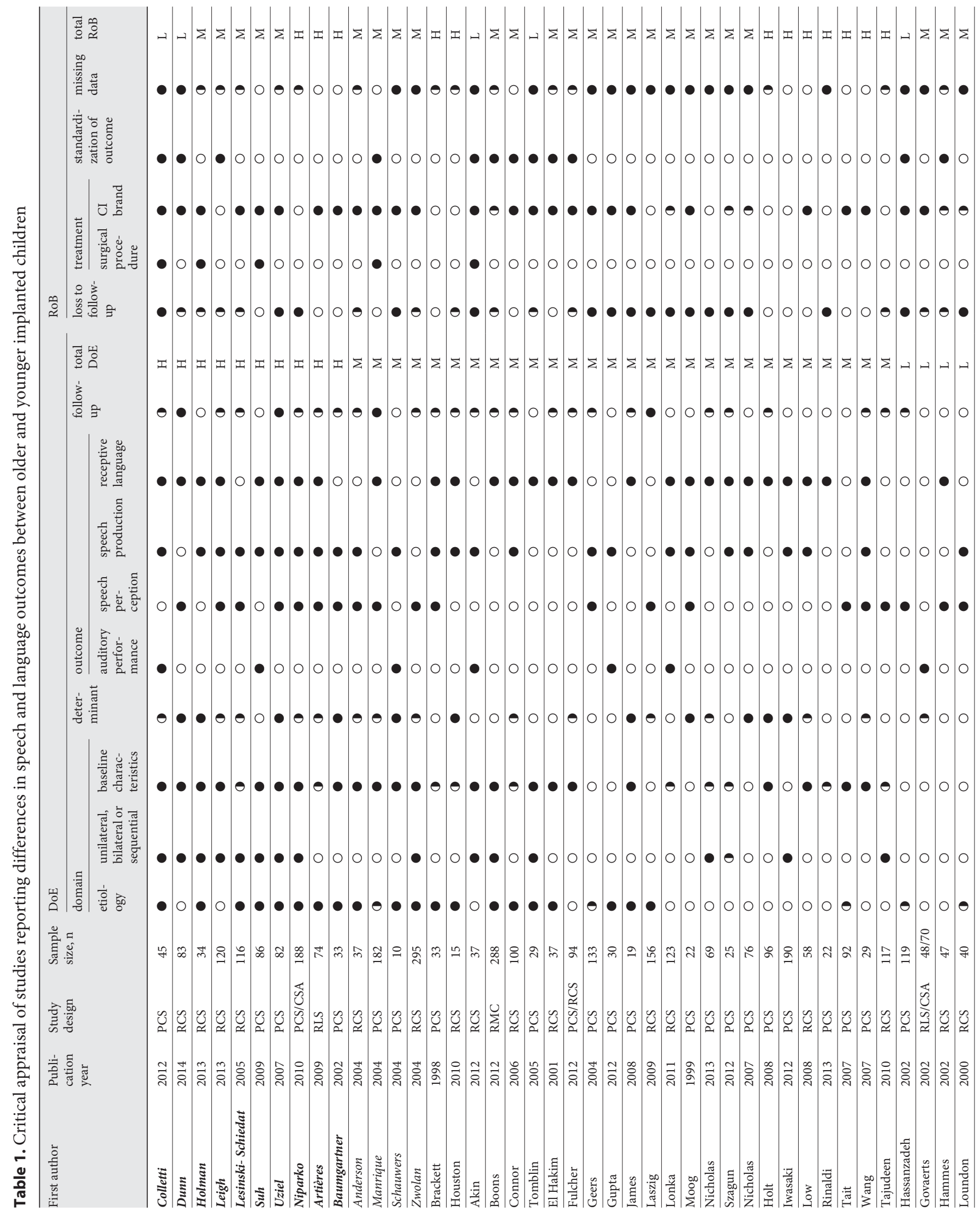




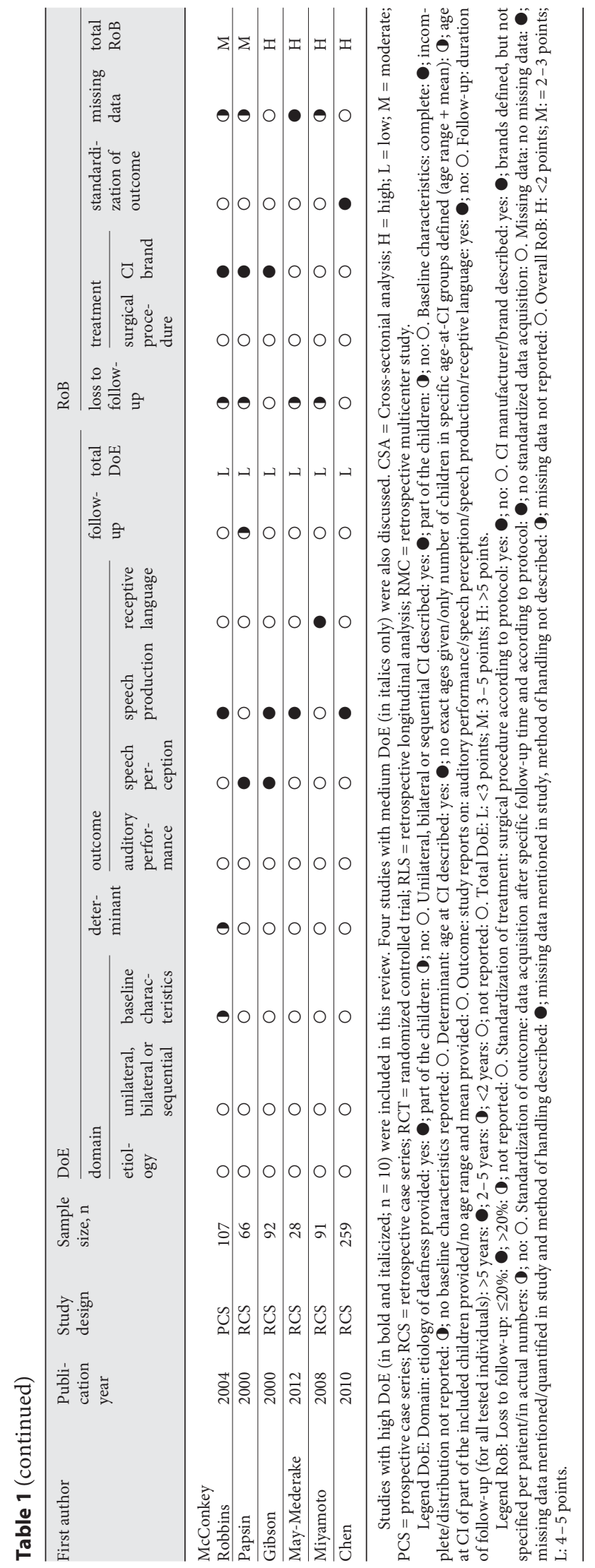

Is There a Speech and Language Developmental Benefit? comparisons, the applied speech and language outcome measures, the follow-up visits and the summary of the principal outcome measures. Original results on postoperative speech and language performance from the papers are presented in the tables and classified according to age at implantation. Data were extracted from original articles by magnifying the figure size to $500 \%$. This paper was written according to the PRISMA (Preferred Reporting Items for Systematic Reviews and Meta-Analyses) statement [Moher et al., 2009]. In the case of homogeneity of: age group comparisons, applied outcome measures, the type of applied statistical analysis and elected follow-up visits, we aimed to combine results of studies in a meta-analysis. When consistency measure $\mathrm{I}^{2}$ was below $50 \%$, we performed statistical pooling of the data using Review Manager (RevMan, version 5.3; Department of Informatics and Knowledge Management, The Nordic Cochrane Center, Copenhagen, Denmark).

\section{Results}

\section{Search Results}

We retrieved 3,360 articles by performing a search on April 24, 2014. After title and abstract screening, 203 articles were assessed for eligibility in full text by two authors (H.B. and I.S.). Sixty-three articles were selected for inclusion (fig. 1). We screened reference lists of selected articles, which did not result in inclusion of additional articles. Figure 1 shows that 15 articles were excluded after full text assessment. Reasons for exclusion were: the use of similar patient cohorts (6 studies), no direct comparison of various CI age groups (8 studies) and 1 study assessed child's health using visual analogue scale scores instead of assessing speech and language outcomes (fig. 1). Three studies were not written in English: 2 German articles and 1 Turkish article. Both reviewers screened the German articles and both a Turkish ear, nose and throat surgeon (V.T.) and a Turkish student (F.Z.) from our department reviewed the Turkish article.

\section{RoB Assessment}

Ten articles showed to contain a high DoE and were, therefore, included in the current review. RoB of included studies ranged from low to high (table 1). Half of the included studies were retrospective and the other 5 studies were prospective case series (table 1). All included studies represented level 2 evidence (grade B). Twenty-six selected studies showed medium DoE. In addition to the aforementioned articles, we decided to discuss the studies with a moderate DoE (> score above 5) and a medium RoB. Due to this decision, 4 studies were included in addition (italicized in table 1). Only 11 included studies defined the etiology of the deafness of their patients. One study 
Table 2. Studies reporting on speech perception outcome measures, CNC, PB-K and GASP, classified according to age at CI and followup time of the included subjects

\begin{tabular}{|c|c|c|c|c|c|c|c|c|c|c|c|}
\hline \multirow[t]{2}{*}{ Authors } & \multirow[t]{2}{*}{ DoE } & \multirow{2}{*}{$\begin{array}{l}\text { Number of } \\
\text { children and } \\
\text { age at CI }\end{array}$} & \multirow{2}{*}{$\begin{array}{l}\text { Outcome } \\
\text { measure }\end{array}$} & \multirow{2}{*}{$\begin{array}{l}\text { Age at } \\
\text { evaluation }\end{array}$} & \multicolumn{6}{|c|}{ FU visits } & \multirow[t]{2}{*}{ Scores } \\
\hline & & & & & $12 \mathrm{~m}$ & $18 \mathrm{~m}$ & $24 \mathrm{~m}$ & $36 \mathrm{~m}$ & $60 \mathrm{~m}$ & $72 \mathrm{~m}$ & \\
\hline $\begin{array}{l}\text { Leigh } \\
\text { et al. } \\
{[2013]}\end{array}$ & $\mathrm{H}$ & $\begin{array}{l}27 \text { aged } 6-12 \mathrm{~m} \\
68 \text { aged } 13-24 \mathrm{~m}\end{array}$ & $\mathrm{CNC}$ & IE: $>2$ years & & & & & & & $\begin{array}{l}\text { After } 2 \text { years of IE: results neither showed a significant } \\
\text { difference between groups nor a significant correlation } \\
\text { between CNC word or phoneme scores and age at } \\
\text { implantation }\end{array}$ \\
\hline $\begin{array}{l}\text { Dunn } \\
\text { et al. } \\
{[2014]}\end{array}$ & $\mathrm{H}$ & $\begin{array}{l}28 \text { aged } 6-24 \mathrm{~m} \\
39 \text { aged } 25-48 \mathrm{~m}\end{array}$ & $\begin{array}{l}\mathrm{CNC}+ \\
\mathrm{PB}-\mathrm{K}\end{array}$ & $\begin{array}{l}\text { CNC: } 6-8 \text { years } \\
\text { PB-K: } 4-5 \text { years }\end{array}$ & & & & & $\mathrm{x}$ & $\mathrm{x}$ & $\begin{array}{l}\text { At } 5 \text { years of age: the younger CI group had higher scores } \\
\text { than the older CI group }(\mathrm{p}<0.001) \text {; the gap between the } \\
\text { two groups was not significant at } 7 \text { years }\end{array}$ \\
\hline $\begin{array}{l}\text { Uziel } \\
\text { et al. } \\
{[2007]}\end{array}$ & $\mathrm{H}$ & $\begin{array}{l}41 \text { aged } 6-48 m \\
41 \text { aged }>48 m\end{array}$ & PB-K & $\begin{array}{l}\text { IE } \\
5 \text { and } 10 \text { years }\end{array}$ & & & & & & & $\begin{array}{l}\text { IE } 5 \text { years: }<4 \text { years: } 73 \% \text { vs. }>4 \text { years: } 57 \% \text {; } \\
\text { IE } 10 \text { years: }<4 \text { years: } 81 \% \text { vs. }>4 \text { years: } 60 \% \\
\text { (ANOVA: } p<0.001 \text { ) } \\
\text { Univariate analysis: group }<4 \text { years: } 67.4 \% \text { above median } \\
\text { vs. }>4 \text { years: } 18 \% \text { above median }(p<0.001)\end{array}$ \\
\hline $\begin{array}{l}\text { Lesinski- } \\
\text { Schiedat } \\
\text { et al. } \\
\text { [2005] }\end{array}$ & $\mathrm{H}$ & $\begin{array}{l}27 \text { aged } 6-12 \mathrm{~m} \\
89 \text { aged } 13-24 \mathrm{~m}\end{array}$ & GASP & & $\mathrm{x}$ & $\mathrm{x}$ & $\mathrm{x}$ & & & & $\begin{array}{l}\text { The development of speech understanding showed better } \\
\text { results at FU }>24 \text { months in the group with } \mathrm{CI}<12 \\
\text { months (n.s.) }\end{array}$ \\
\hline $\begin{array}{l}\text { Zwolan } \\
\text { et al. } \\
{[2004]}\end{array}$ & M & $\begin{array}{l}59 \text { aged } 6-36 \mathrm{~m} \\
236 \text { aged } 37 \text { to } \\
>48 \mathrm{~m}\end{array}$ & $\begin{array}{l}\text { GASP-S + } \\
\text { GASP-W }\end{array}$ & & $\mathrm{x}$ & & $\mathrm{x}$ & $\mathrm{x}$ & & & $\begin{array}{l}\text { 1-year FU: mean score of group } 4 \text { better than those of } \\
\text { group } 1(\mathrm{n}=59 ; \mathrm{p}=0.01) \text { and group } 2(\mathrm{n}=85 ; \mathrm{p}=0.004) \text {; } \\
\text { mean score of group } 5 \text { better than those of group } 1(\mathrm{p}= \\
0.02) \text { and group } 2(\mathrm{p}=0.01) \\
\text { 24- and } 36 \text {-month FU: mean score of group } 1 \text { better than } \\
\text { those of the } 4 \text { other groups (n.s.) }\end{array}$ \\
\hline
\end{tabular}

ANOVA = Analysis of variance; $\mathrm{CI}=$ cochlear implantation; $\mathrm{CNC}=$ consonant-nucleus-consonant; $\mathrm{FU}=$ follow-up; GASP = Glendonald auditory screening procedure; GASP-W/ GASP-S = GASP for words/sentences; $\mathrm{H}=$ high; $\mathrm{IE}=$ implant experience; $\mathrm{m}=$ months; $\mathrm{n} . \mathrm{s}$. = nonsignificant; $\mathrm{PB}-\mathrm{K}=$ phonetically balanced kindergarten.

defined whether the cause of deafness was (un)known, but did not define exact etiologies [Manrique et al., 2004]. Although 5 studies did not define whether patients were unilaterally or bilaterally implanted, 9 studies did mention how many implants were used in each individual patient (table 1). Twelve of the 14 studies clearly defined baseline characteristics. The exact age at CI of all implanted individuals was provided in 5 studies. Eight studies provided the mean age at $\mathrm{CI}$ and the age range of PCI patients in the study groups. The remaining study provided the mean age at $\mathrm{CI}$ in months, but did not define the exact age range of each age group. Six of the included studies tested children on 3 speech and language outcomes: 4 studies on speech production, speech perception and receptive language and 2 studies on auditory performance, speech production and receptive language. Although we aimed to include studies with a minimal follow-up of 5 years, only 3 of the selected studies had a follow-up that was longer than 5 years. Eight studies had a follow-up between 2 and 5 years and 3 studies shorter than 2 years. In 4 studies, the loss to follow-up was less than $20 \%$ and in 6 studies above 20\%; 3 studies did not report patients lost to follow-up. The applied surgical procedure was described in 4 studies. The type of cochlear device used was mentioned in 12 of the 14 studies. In only 4 studies, out- come measurements were performed according to a defined protocol. Four studies defined the method of handling of missing data. Five studies mentioned the amount of missing data, but did not describe how these missing values were accounted for in their analysis.

\section{Study Characteristics}

The age range of the children in the included studies varied widely (tables $2-5$ ). We identified 6 studies with a high DoE that compared children implanted under the age of 1 year with children implanted between 12 and 24 months. Inclusion of these studies resulted in the identification of 125 children implanted under the age of 1 year (tables 2-5). The timing of assessments of children included ranged from preoperative measurements (5 studies) to 9 years of implant experience (IE; tables 2-5).

\section{Data Analysis}

The study results are presented in tables $2-5$, subdivided by the four categories of speech and language development: receptive language, speech perception, speech production and auditory performance (tables $2-5$ ). Studies are enumerated by similarly applied outcome measures to quantify speech and language development. Due to the heterogeneity of groups regarding age at CI, out- 
Table 3. Studies reporting on speech production outcome measures, DEAP, SIR, (IT-)MAIS and LittlEARS ${ }^{\circledR}$, classified according to age at CI and follow-up time of the subjects included

\begin{tabular}{|c|c|c|c|c|c|c|c|c|c|c|c|c|c|}
\hline \multirow[t]{2}{*}{ Authors } & \multirow[t]{2}{*}{ DoE } & \multirow{2}{*}{$\begin{array}{l}\text { Number of } \\
\text { children and } \\
\text { age at CI }\end{array}$} & \multirow{2}{*}{$\begin{array}{l}\text { Outcome } \\
\text { measure }\end{array}$} & \multirow{2}{*}{$\begin{array}{l}\text { Age at } \\
\text { evaluation }\end{array}$} & \multirow{2}{*}{$\begin{array}{l}\text { Pre- } \\
\text { op. }\end{array}$} & \multicolumn{7}{|l|}{$\mathrm{FU}$} & \multirow[t]{2}{*}{ Scores } \\
\hline & & & & & & $3 \mathrm{~m}$ & $6 \mathrm{~m}$ & $12 \mathrm{~m}$ & $18 \mathrm{~m}$ & $24 \mathrm{~m}$ & $48 \mathrm{~m}$ & $60 \mathrm{~m}$ & \\
\hline $\begin{array}{l}\text { Leigh } \\
\text { et al. } \\
{[2013]}\end{array}$ & $\mathrm{H}$ & $\begin{array}{l}16 \text { aged } 6-12 \mathrm{~m} \\
16 \text { aged } 13-24 \mathrm{~m}\end{array}$ & DEAP & $\begin{array}{l}\mathrm{IE} \\
>2 \text { years }\end{array}$ & & & & & & & & & $\begin{array}{l}\text { IE, } 2 \text { years: group } 1 \text { : DEAP } 93 \% \text { and group } 2: \text { DEAP } 85 \% \\
(p=0.033) \text {; both groups performed poorer than their } \\
\text { hearing peers }(p=0.002, p=0.001) ; \text { mean speech } \\
\text { production score was correlated with age at } \mathrm{CI}(\mathrm{p}=0.014)\end{array}$ \\
\hline $\begin{array}{l}\text { Artières } \\
\text { et al. } \\
\text { [2009] }\end{array}$ & $\mathrm{H}$ & $\begin{array}{l}32 \text { aged } 6-24 \mathrm{~m} \\
15 \text { aged } 25-36 \mathrm{~m} \\
14 \text { aged } 37-48 \mathrm{~m} \\
13 \text { aged }>48 \mathrm{~m}\end{array}$ & SIR & $\begin{array}{l}4,5,6,7 \\
\text { or } 8 \text { years }\end{array}$ & & & & & & & $\mathrm{x}$ & $\mathrm{x}$ & $\begin{array}{l}\text { No significant differences between the performance of } \\
\text { groups } 1 \text { and } 2 \text { and between groups } 2 \text { and } 3 \text { at } 4 \text { years of } \\
\text { age; median SIR for group } 3 \text { was significantly lower than } \\
\text { for group } 1 \text { (no p value provided) }\end{array}$ \\
\hline $\begin{array}{l}\text { Uziel } \\
\text { et al. } \\
{[2007]}\end{array}$ & $\mathrm{H}$ & $\begin{array}{l}41 \text { aged } 6-48 m \\
41 \text { aged }>48 m\end{array}$ & SIR & $\begin{array}{l}\text { IE } \\
10 \text { years }\end{array}$ & & & & & & & & & $\begin{array}{l}\text { IE, } \geq 10 \text { years: children implanted }<4 \text { years demonstrated } \\
65 \% \text { (vs. } 12 \%>4 \text { years) SIR greater than the median }(\mathrm{p}< \\
0.001) \\
\text { IE, } 10 \text { years: }<4 \text { years: mean SIR } 4.3, \\
>4 \text { years: mean SIR } 3.4 \text { (ANOVA: } \mathrm{p}<0.0005)\end{array}$ \\
\hline $\begin{array}{l}\text { Holman } \\
\text { et al. } \\
\text { [2013] }\end{array}$ & $\mathrm{H}$ & $\begin{array}{l}17 \text { aged } 6-12 \mathrm{~m} \\
17 \text { aged } 13-24 \mathrm{~m}\end{array}$ & $\begin{array}{l}\text { IT-MAIS } \\
\text { or } \\
\text { LittlEARS }^{\circledR}\end{array}$ & & $\mathrm{x}$ & $\mathrm{x}$ & $\mathrm{x}$ & $\mathrm{x}$ & & & & & $\begin{array}{l}\text { All patients made significant gains after CI; children } \\
\text { implanted before } 12 \text { months or younger reached } \\
\text { age-appropriate speech and language skills by } 24 \text { months } \\
\text { of age vs. } 41 \text { months for the older pediatric control } \\
\text { group ( } p<0.05)\end{array}$ \\
\hline $\begin{array}{l}\text { Lesinski- } \\
\text { Schiedat } \\
\text { et al. } \\
\text { [2005] }\end{array}$ & $\mathrm{H}$ & $\begin{array}{l}27 \text { aged } 6-12 \mathrm{~m} \\
89 \text { aged } 13-24 \mathrm{~m}\end{array}$ & MAIS & & $\mathrm{x}$ & $\mathrm{x}$ & $\mathrm{x}$ & $\mathrm{x}$ & $\mathrm{x}$ & $\mathrm{x}$ & & & $\begin{array}{l}\text { 3-month FU: good response to noise in } 75 \% \text { of the early } \\
\text { CI group vs. } 69 \% \text { of the later CI group; } 18 \text {-month FU: in } \\
97 \% \text { of the earlier implanted group (n.s.); } \\
\text { 3-month FU: identification of noise in } 59 \% \text { of the } \\
\text { younger CI group vs. } 48 \% \text { of the older CI group (n.s.); } \\
\text { 24-month FU: in } 97 \% \text { of the younger CI group and } 87 \% \\
\text { of the older CI group }\end{array}$ \\
\hline
\end{tabular}

ANOVA = Analysis of variance; $\mathrm{CI}=$ cochlear implantation; DEAP = diagnostic evaluation of articulation and phonology; DoE = directness of evidence; FU = follow-up; $\mathrm{H}=$ high; $\mathrm{IE}=$ implant experience; (IT-)MAIS = (Infant-Toddler) Meaningful Auditory Integration Scale; $\mathrm{m}=$ months; $\mathrm{n} . \mathrm{s} .=$ nonsignificant; SIR $=$ speech intelligibility rate.

come measures, applied statistical analysis and elected follow-up visits, we did not perform statistical pooling of the data (tables 2-5).

\section{Speech Perception Outcomes}

Speech perception of included studies was assessed using consonant-nucleus-consonant (CNC), phonetically balanced kindergarten (PB-K) and Glendonald auditory screening procedure (GASP) scores (table 2).

Leigh et al. [2013] did not find significant differences when comparing CNC word or phoneme scores between groups implanted between 6-12 and 13-24 months at 2 years of IE. However, Dunn et al. [2014] showed that younger implanted children ( $<24$ months) performed superior on combined CNC and PB-K-scores at 5 years of age $(\mathrm{p}<0.001)$ compared to older implanted children. Scores of the 2 groups remained significantly different $(\mathrm{p}<0.05)$ at $8,9,10$ and 12 years of age. Uziel et al. [2007] tested children on $\mathrm{PB}-\mathrm{K}$ scores at 5- and 10-year followup visits and showed that speech perception skills continued to grow after 5 years of IE: no plateau was reached in the children. The authors detected a positive effect for implantation under the age of 4 years $(p<0.00001)$. Uziel et al. [2007] showed higher speech perception scores

Is There a Speech and Language

Developmental Benefit? compared to the modeled values at 60 months of Dunn et al. [2014]: $55 \%$ at 7 years of age ( $<2$ years) and $48 \%$ at 8 years of age (2-4 years). Both studies testing children on GASP scores [Zwolan et al., 2004; Lesinski-Schiedat et al., 2005] found older implanted children (implanted above 12 and 36 months, respectively) to perform better at the 12-month follow-up. However, after 24 months of follow-up, the youngest implanted children $(<12$ months [Lesinski-Schiedat et al., 2005] and between 1 and 3 years [Zwolan et al., 2004]) outperformed the older implanted children (nonsignificant) in both studies (table 2).

\section{Speech Production Outcomes}

Speech production was assessed using the diagnostic evaluation of articulation and phonology (DEAP), speech intelligibility rate (SIR) and Infant-Toddler Meaningful Auditory Integration Scale (IT-MAIS) in the included studies (table 3). Children are currently implanted in their prelexical period; therefore, a major landmark in their development becomes the onset of babbling [Schauwers et al., 2004]. Normally, babbling occurs between 6-10 months [Koopmans-van Beinum and van der Stelt, 1986; Oller, 1986]. Schauwers et al. [2004] tested the onset of the babbling spurt postoperatively and results showed that the earlier the chil- 
Table 4. Studies reporting on receptive language outcome measures: PLS (-3, -4), OWLS, CELF-3, K-PVT, PPVT (-3, -4, -R), RDLS (-3), CELF-3 and MB-CDI scores, classified according to age at CI and follow-up time of the subjects included

\begin{tabular}{|c|c|c|c|c|c|c|c|c|c|c|c|c|}
\hline \multirow[t]{2}{*}{ Authors } & \multirow[t]{2}{*}{$\mathrm{DoE}$} & \multirow{2}{*}{$\begin{array}{l}\text { Number of } \\
\text { children and } \\
\text { age at CI }\end{array}$} & \multirow{2}{*}{$\begin{array}{l}\text { Outcome } \\
\text { measure }\end{array}$} & \multirow{2}{*}{$\begin{array}{l}\text { Age at } \\
\text { evaluation }\end{array}$} & \multirow{2}{*}{$\begin{array}{l}\text { Pre- } \\
\text { op. }\end{array}$} & \multicolumn{6}{|l|}{$\mathrm{FU}$} & \multirow[t]{2}{*}{ Scores } \\
\hline & & & & & & $3 \mathrm{~m}$ & $6 \mathrm{~m}$ & $12 \mathrm{~m}$ & $24 \mathrm{~m}$ & $36 \mathrm{~m}$ & $48 \mathrm{~m} \quad 60 \mathrm{~m}$ & \\
\hline $\begin{array}{l}\text { Holman } \\
\text { et al. [2013] }\end{array}$ & $\mathrm{H}$ & $\begin{array}{l}17 \text { aged } 0-12 \mathrm{~m} \\
17 \text { aged } 13-24 \mathrm{~m}\end{array}$ & $\begin{array}{l}\text { PLS-4 + } \\
\text { OWLS }\end{array}$ & & $\mathrm{x}$ & & & $\mathrm{x}$ & $\mathrm{x}$ & $\mathrm{x}$ & & $\begin{array}{l}\text { Children implanted }<12 \text { months tended to } \\
\text { demonstrate significantly better receptive } \\
\text { language abilities }(p<0.05) \text { than children } \\
\text { implanted between } 13 \text { and } 24 \text { months }\end{array}$ \\
\hline $\begin{array}{l}\text { Niparko } \\
\text { et al. [2010] }\end{array}$ & $\mathrm{H}$ & $\begin{array}{l}72 \text { aged } 0-12 \mathrm{~m} \\
64 \text { aged } 13-24 \mathrm{~m} \\
52 \text { aged } 25 \text { to }>48 \mathrm{~m}\end{array}$ & RDLS & & $\mathrm{x}$ & & & & & $\mathrm{x}$ & & $\begin{array}{l}\text { Higher rates of both comprehension and } \\
\text { expression of RDLS language scales in } \\
\text { children implanted }<18 \text { months vs. } \\
\text { children undergoing implantation between } \\
18 \text { and } 36 \text { and }>36 \text { months of age }(\mathrm{p}<0.05)\end{array}$ \\
\hline $\begin{array}{l}\text { Dunn } \\
\text { et al. [2014] }\end{array}$ & $\mathrm{H}$ & $\begin{array}{l}13 \text { aged } 0-12 \mathrm{~m} \\
26 \text { aged } 13-24 \mathrm{~m}\end{array}$ & CELF-3 & $\begin{array}{l}7,8 \text { and } \\
9 \text { years }\end{array}$ & & & & & & & & $\begin{array}{l}\text { At } 7 \text { years of age, the youngest-implanted } \\
\text { group achieved scores that were } 12 \text { points } \\
\text { higher than the older-implanted group } \\
(\mathrm{p}=0.01) \text {; by } 10 \text { and up to } 11 \text { years of age, } \\
\text { there was no significant difference } \\
\text { between both groups (n.s.) }\end{array}$ \\
\hline $\begin{array}{l}\text { Artières } \\
\text { et al. [2009] }\end{array}$ & $\mathrm{H}$ & $\begin{array}{l}32 \text { aged } 0-24 \mathrm{~m} \\
15 \text { aged } 25-36 \mathrm{~m} \\
14 \text { aged } 36-48 \mathrm{~m} \\
13 \text { aged } 4-5 \text { years }\end{array}$ & $\begin{array}{l}\text { PPVT-R } \\
\text { (French) }\end{array}$ & & & & & & & & $\mathrm{x}$ & $\begin{array}{l}4 \text { - and } 5 \text {-year FU: significant difference } \\
\text { between groups } 1(<2 \text { years) and } 2(2-3 \\
\text { years; } p<0.05) \text {; receptive language levels } \\
\text { for group } 1 \text { reached a normal lexical level } \\
\text { by } 4 \text { years of age }\end{array}$ \\
\hline $\begin{array}{l}\text { Colletti } \\
\text { et al. [2012] }\end{array}$ & $\mathrm{H}$ & $\begin{array}{l}12 \text { aged } 2-6 \mathrm{~m} \\
9 \text { aged } 7-12 \mathrm{~m} \\
11 \text { aged } 13-18 \mathrm{~m} \\
13 \text { aged } 19-24 \mathrm{~m}\end{array}$ & PPVT-R & & & & & & $\mathrm{x}$ & $\mathrm{x}$ & $\mathrm{x}$ & $\begin{array}{l}\text { The youngest group achieved better } \\
\text { results than CI groups implanted }>12 \\
\text { months } \\
<6 \text { vs. }>12 \text { months: } 24 \text {-month FU: } \mathrm{p}< \\
0.001 ; 36 \text {-month FU: } \mathrm{p}<0.05 ; 48 \text {-month } \\
\text { FU: } \mathrm{p}<0.001 \text {; } \\
\text { no significant difference in PPVT-R } \\
\text { between age group } 1 \text { and } 2\end{array}$ \\
\hline $\begin{array}{l}\text { Leigh } \\
\text { et al. } \\
{[2013]}\end{array}$ & $\mathrm{H}$ & $\begin{array}{l}21 \text { aged } 7-12 \mathrm{~m} \\
40 \text { aged } 13-24 \mathrm{~m}\end{array}$ & $\begin{array}{l}\text { PPVT-3 } \\
\text { PPVT-4 }\end{array}$ & & & & & & & $\mathrm{x}$ & & $\begin{array}{l}\text { 36-month FU: group } 1 \text { children achieved } \\
\text { higher receptive vocabulary standard } \\
\text { scores than those in group } 2(\mathrm{p}=0.033) \text {; } \\
\text { PPVT standard score had a significant } \\
\text { correlation with age at } \mathrm{CI}(\mathrm{p}<0.001)\end{array}$ \\
\hline $\begin{array}{l}\text { Manrique } \\
\text { et al. } \\
{[2004]}\end{array}$ & M & $\begin{array}{l}94 \text { aged } 0-36 \mathrm{~m} \\
88 \text { aged } 4-14 \text { years }\end{array}$ & $\begin{array}{l}\text { PPVT } \\
\text { RDLS } \\
\text { (Spanish) }\end{array}$ & & $\mathrm{x}$ & & & $\mathrm{x}$ & $\mathrm{x}$ & $\mathrm{x}$ & $\mathrm{x}$ & $\begin{array}{l}\text { Children implanted at } 0-3 \text { years followed } \\
\text { an almost normal acquisition of vocabula- } \\
\text { ry (PPVT), whereas older implanted } \\
\text { children had a deviation of almost } 3 \text { years } \\
\text { from normal baseline; RDLS scores: } \\
\text { children implanted }<36 \text { months showed a } \\
\text { delay of } 2 \text { years vs. NH peers; older im- } \\
\text { planted children deviated }>4 \text { years }\end{array}$ \\
\hline $\begin{array}{l}\text { Suh et al. } \\
{[2009]}\end{array}$ & $\mathrm{H}$ & $\begin{array}{l}22 \text { aged } 0-24 \mathrm{~m} \\
23 \text { aged } 25-36 \mathrm{~m} \\
19 \text { aged } 36-48 \mathrm{~m} \\
22 \text { aged } 4-6 \text { years }\end{array}$ & K-PVT & & & $\mathrm{x}$ & $\mathrm{x}$ & $\mathrm{x}$ & $\mathrm{x}$ & $\mathrm{x}$ & & $\begin{array}{l}\text { The improvement in the K-PVT percentile } \\
\text { score was significantly higher for the } \\
\text { group implanted at a younger age }(\mathrm{p}= \\
0.037) \text {; this group showed a more rapid } \\
\text { improvement }(\mathrm{p}=0.004) \text {; children im- } \\
\text { planted }<2 \text { years caught up with their NH } \\
\text { peers after } 2-3 \text { years of IE; children } \\
\text { implanted }>3 \text { years achieved only a score } \\
\text { at the } 20 \text { th percentile of their NH peers }\end{array}$ \\
\hline $\begin{array}{l}\text { Uziel } \\
\text { et al. } \\
{[2007]}\end{array}$ & $\mathrm{H}$ & $\begin{array}{l}41 \text { aged } 0-48 m \\
41 \text { aged }>48 m\end{array}$ & PPVT-R & $\begin{array}{l}\mathrm{IE} \\
10 \text { years }\end{array}$ & & & & & & & & $\begin{array}{l}\text { 10-year FU: children implanted }<4 \text { years: } \\
\text { PPVT-R 2.8, implanted }>4 \text { years; PPVT-R: } \\
2.3(\mathrm{p}<0.05)\end{array}$ \\
\hline
\end{tabular}

CELF = Clinical Evaluation of Language Fundamentals; $\mathrm{FU}=$ follow-up $; \mathrm{H}=$ high $; \mathrm{HL}=$ hearing loss $\mathrm{K}-\mathrm{PVT}=\mathrm{Korean} \mathrm{PPVT} ; \mathrm{M}=\mathrm{medium} ; \mathrm{m}=\mathrm{month} ; \mathrm{OWLS}=$ oral and written language skills; PLS = Preschool Language Scale; PPVT = Peabody Picture Vocabulary Test; RDLS = Reynell Developmental Language Scale.

dren were implanted, the more consistent their results were with the development of their normal hearing $(\mathrm{NH})$ peers.

In line with this finding, Leigh et al. [2013] showed a significant effect $(\mathrm{p}<0.05)$ for early implanted children $(<12$ months) compared to later implanted children at 2 -year IE on DEAP scores. Both tested groups performed poorer than their hearing peers $(\mathrm{p}=0.002$ and $\mathrm{p}=0.001$, respectively) (table 3).

Two included studies [Uziel et al., 2007; Artières et al., 2009] compared groups implanted before and after 48 
Table 5. Studies reporting on auditory performance outcome measures, CAP scores, classified according to age at CI and follow-up time of the subjects included

\begin{tabular}{|c|c|c|c|c|c|c|c|c|c|c|c|}
\hline \multirow[t]{2}{*}{ Authors } & \multirow[t]{2}{*}{ DoE } & \multirow{2}{*}{$\begin{array}{l}\text { Number of } \\
\text { children and } \\
\text { age at CI }\end{array}$} & \multirow{2}{*}{$\begin{array}{l}\text { Outcome } \\
\text { measure }\end{array}$} & \multirow{2}{*}{$\begin{array}{l}\text { Pre- } \\
\text { op. }\end{array}$} & \multicolumn{6}{|l|}{ FU } & \multirow[t]{2}{*}{ Scores } \\
\hline & & & & & $3 \mathrm{~m}$ & $6 \mathrm{~m}$ & $12 \mathrm{~m}$ & $18 \mathrm{~m}$ & $24 \mathrm{~m}$ & $36 \mathrm{~m} 48 \mathrm{~m}$ & \\
\hline $\begin{array}{l}\text { Colletti } \\
\text { et al. [2012] }\end{array}$ & $\mathrm{H}$ & $\begin{array}{l}12 \text { aged } 0-6 \mathrm{~m} \\
9 \text { aged } 7-12 \mathrm{~m} \\
11 \text { aged } 13-18 \mathrm{~m} \\
13 \text { aged } 19-24 \mathrm{~m}\end{array}$ & CAP-II & & & & & & & $\mathrm{x}$ & $\begin{array}{l}\text { 48-month FU: cohort implanted }<6 \text { months reached } \\
\text { higher scores than all other implanted groups }(\mathrm{p}<0.001) \\
\text { this youngest group showed no significant difference } \\
\text { from the NH group }\end{array}$ \\
\hline $\begin{array}{l}\text { Schauwers } \\
\text { et al. [2004] }\end{array}$ & M & 10 aged $7-18 \mathrm{~m}$ & CAP & & & & $\mathrm{x}$ & $\mathrm{x}$ & & & $\begin{array}{l}\text { The children implanted in their } 1 \text { st year of life showed a } \\
\text { normal CAP development as early as } 3 \text { months after CI, } \\
\text { whereas children implanted in their } 2 \text { nd year of life } \\
\text { needed up to } 12 \text { months to reach an age-appropriate } \\
\text { CAP level; children who received their implant at } \\
\text { approximately } 18 \text { months of age lag a bit behind their } \\
\text { NH peers, whereas those receiving their implant in their } \\
\text { 1st year of life follow the normal line (n.s.) }\end{array}$ \\
\hline $\begin{array}{l}\text { Suh et al. } \\
\text { [2009] }\end{array}$ & $\mathrm{H}$ & $\begin{array}{l}22 \text { aged } 0-24 \mathrm{~m} \\
23 \text { aged } 25-36 \mathrm{~m} \\
19 \text { aged } 37-48 \mathrm{~m} \\
22 \text { aged }>48 \mathrm{~m}\end{array}$ & CAP imp. & $\mathrm{x}$ & $\mathrm{x}$ & $\mathrm{x}$ & $\mathrm{x}$ & & $\mathrm{x}$ & $\mathrm{x}$ & $\begin{array}{l}\text { The improvement in the CAP score was not different } \\
\text { among the groups (n.s.); the youngest age group did } \\
\text { show a more rapid improvement (a steeper inclination) } \\
\text { than the other groups }(\mathrm{p}=0.002)\end{array}$ \\
\hline
\end{tabular}

$\mathrm{CAP}=$ Categories of Auditory Performance; $\mathrm{CI}=$ cochlear implantation; $\mathrm{DoE}=$ directness of evidence; $\mathrm{FU}=$ follow-up; $\mathrm{H}=\mathrm{high} ; \mathrm{imp} .=\mathrm{improvement} ; \mathrm{M}=\mathrm{medium} ; \mathrm{m}=\mathrm{months} ;$ $\mathrm{NH}=$ normal hearing; n.s. $=$ nonsignificant.

months on SIR scores; however, follow-up moments were different (table 3). Artières et al. [2009] assessed young children $(<2$ years) who reached ceiling scores from 6 years onwards and could not confirm significant differences between groups. Uziel et al. [2007] showed that after 10 years of IE, the mean SIR score of the group of children implanted before 4 years was significantly higher than in children implanted after 4 years $(\mathrm{p}<$ 0.0005).

Two studies compared children on IT-MAIS scores at the same follow-up visits: 3, 6 and 12 months [LesinskiSchiedat et al., 2005; Holman et al., 2013]. Studies compared similar age groups, but 1 study [Holman et al., 2013] combined IT-MAIS with LittlEARS questionnaire scores, whereas only MAIS scores were applied in the study of Lesinski-Schiedat et al. [2005]. Holman et al. [2013] found over $60 \%$ of correct scores of their youngest implanted children at the 12-month follow-up. Similarly, Lesinski-Schiedat et al. [2005] found over 70\% correct answers at several subsets of the MAIS scores on their youngest group of implanted patients ( $<12$ months) at the 1-year follow-up. In both studies, at 21 months of age [Holman et al., 2013] and 24 months of follow-up [Lesinski-Schiedat et al., 2005], scores of both age groups varied between 80 and $100 \%$ correct scores, without differences with respect to age at CI being identified between groups.

\section{Receptive Language Outcome Measures}

Receptive language was measured on oral and written language skills (OWLS), Clinical Evaluation of Language Fundamentals (CELF), Preschool Language Scale (PLS), Peabody Picture Vocabulary Test (PPVT) and Reynell Developmental Language Scale (RDLS) scores (table 4).

Holman et al. [2013] assessed PLS-4 and OWLS scores and concluded that children implanted before 12 months reached speech and language skills by 24 months of age compared to 41 months for the group implanted between 12 and 24 months of age ( $<0.05)$. Niparko et al. [2010] confirmed significantly higher rates of both comprehension and expression of language (RDLS scores) in children implanted before 18 months compared with children undergoing implantation between 18 and 36 months of age, and especially compared to children implanted after 36 months of age. Manrique et al. [2004] applied similar RDLS scores and showed that children implanted before 36 months had a delay of 2 years compared to $\mathrm{NH}$ peers, whereas older ( $>36$ months) implanted children deviated more than 4 years from their $\mathrm{NH}$ peers. A comparison on CELF-3 scores [Dunn et al., 2014] indicated that at 7 years of age, the younger-implanted group ( $<2$ years) achieved scores that were on average 12 points higher than the later implanted group $(\mathrm{p}=0.01)$.

Colletti et al. [2012] used the revised PPVT (PPVT-R) to assess receptive language measures, and their results showed that the youngest group (implanted between 2 and 6 months) significantly outperformed children implanted 
above 1 year $(\mathrm{p}<0.001)$, an effect that remained significant till 48 months of follow-up. A comparison [Colletti et al., 2012] between children implanted before 6 months $(n=12)$ and at $6-12$ months $(n=9)$ failed to show a significant difference at any follow-up visit. Artières et al. [2009] compared PPVT-R scores of children implanted before and after the age of 2 years, and found a statistically significant difference between groups followed up at 1 year $(\mathrm{n}=32)$ and 2 years $(\mathrm{n}=15 ; \mathrm{p}<0.05)$ and at 4 and 5 years (table 4$)$. Uziel et al. [2007] showed children implanted before the age of 4 years outperformed children implanted after 4 years at the 10-year follow-up on PPVT-R scores ( $\mathrm{p}<0.05$ ).

The PPVT-3 and PPVT- 4 are highly correlated [Dunn and Dunn, 2007]. Leigh et al. [2013] compared data of groups with different age at CI $(<1$ vs. $>1$ year $)$ at the 36-month follow-up, tested on both PPVT scores. The authors found younger children to achieve higher receptive vocabulary scores compared to older implanted children $(\mathrm{p}=0.033)$.

Suh et al. [2009] showed patients implanted before 24 months to catch up with the NH population after 2-3 years (Korean PPVT scores). In addition, after 2 and even after 3 years of follow-up, the children implanted after 3 years caught up with only the 20th percentile of $\mathrm{NH}$ children. Therefore, Suh et al. [2009] concluded that 2 years of age seems to be the critical CI time point for children.

\section{Auditory Performance}

In the included studies, auditory performance was assayed using Categories of Auditory Performance (CAP) scores only (table 5).

At the 4-year follow-up, Colletti et al. [2012] found their youngest CI group (implanted between 2 and 6 months) to outperform their peers with later $\mathrm{CI}$ on the second version of the CAP (CAP-II) score $(\mathrm{p}<0.001)$. Their results indicated that using the CAP-II score is needed to show differences between children implanted before 2 years of age. No significant difference was seen when their youngest $\mathrm{CI}$ group was compared to $\mathrm{NH}$ peers. Schauwers et al. [2004] compared children at the 12-month follow-up and found that $80 \%$ of the children operated between 6 and 18 months achieved a CAP score between 5 and 6 . The authors concluded that children with $\mathrm{CI}$ at approximately 18 months of age lag a bit behind their $\mathrm{NH}$ peers, whereas those receiving their implant in their 1st year of life follow the normal line (nonsignificant). Suh et al. [2009] found their youngest CI cohort to show a more rapid CAP improvement than their older CI peers. However, this CAP improvement was not significantly different between groups regarding age at CI.

\section{Discussion}

Our review shows consistent evidence for the benefit of early PCI, but the literature remains indistinct on defining the additional speech and language benefits of CI before the age of 12 months. The number of available studies was substantial. Ten of the 14 discussed studies showed to contain high DoE, but RoB ranged from low to moderate.

The best available evidence is based on independent subjective outcome measures and indicates that implantation before the age of 2 is beneficial when considering speech perception (on combined $\mathrm{PB}-\mathrm{K}$ and $\mathrm{CNC}$ but not on GASP scores) [Leigh et al., 2013; Dunn et al., 2014; Lesinski-Schiedat et al., 2005]. Implantation before 12 months resulted in better speech production (DEAP and IT-MAIS) [Ching et al., 2013; Leigh et al., 2013], auditory performance (CAP-II score) [Colletti et al., 2012] and two out of the five receptive language scores (combined PLS-4 and OWLS and PPVT scores) [Colletti et al., 2012; Leigh et al., 2013; Holman et al., 2013]. One study showed that implantation before 6 months resulted in superior 4-year auditory performance (CAP-II) [Colletti et al., 2012]. Although the latter study of Colletti et al. [2012] showed safe and effective results, the majority of ENT surgeons will refrain from this elective surgery before the age of 12 months [Bronstein, 2012]. The exception for performing CI in early infancy remains the occurrence of deafness following meningitis [Bronstein, 2012]. However, in Europe, a trend to implanting children before their 1st year of life is emerging.

Due to concerns regarding unreliable preoperative auditory assessment, underdeveloped anatomy, lack of FDA approval [Bronstein, 2012] and a possibly increased risk for anesthetic complications, CI has not been performed widely in the population under 1 year [Holman et al., 2013]. However, increasing evidence shows that CI can be performed without increased risk of anesthetic and surgical complications in this population. Four selected studies reported on complication rates in children [Colletti et al., 2012; Holman et al., 2013; Lesinski-Schiedat et al., 2005; Manrique et al., 2004] of which 3 studies [Colletti et al., 2012; Holman et al., 2013; Lesinski-Schiedat et al., 2005] included children operated before the age of 12 months. All 3 studies did not report any significant difference in anesthetic or surgical complications between early ( $<12$ months) and later ( $>12$ months) implanted patients. Colletti et al. [2012] did report that young children $(2-6$ months) experienced a significantly $(\mathrm{p}<0.05)$ higher heart rate; however, this reflected an age-appropiate heart rate for these young children. 
We found variation in the recommended age children should be implanted to be able to close gaps in speech and language delays compared to $\mathrm{NH}$ peers. The recommended age for implantation varied from 6 to 24 months [Niparko et al., 2010; Boons et al., 2012]. Coene et al. [2011] stated that implantation before the age of 16 months will prevent speech and language delays; however, this small study sample lacked a comparison of ageat-CI groups. Svirsky et al. [2004] used developmental trajectory analysis and showed that implantation before the age of 2 years resulted in significant speech and language advantages. The identified variation in recommended implantation age might be the consequence of the inconsistent, incomplete and conflicting evidence that was identified from the current literature.

To monitor the initial positive 'age-at-CI effect', adequate longitudinal analysis is essential to account for assessment of confounding effects. For example, Dunn et al. [2014] showed initial significant differences at the 7-year follow-up among age-at-CI groups, but no differences were found at the 10- and 11-year follow-up (table 4). The initial speech and language growth rate might be higher in early implanted children due to auditory stimulation during the sensitive developmental period [Tajudeen et al., 2010]. Alternatively, this group has the advantage of earlier diagnosis, earlier hearing aid intervention, more time to learn to listen with the implant ('starting early') and earlier education intervention. Therefore, the lower performance level in older implanted children might be a consequence of their lower level of device experience [Tomblin et al., 2005; Dettman et al., 2007]. Tajudeen et al. [2010] underlined this in their analysis by showing that younger implanted children outperformed older implanted children; however, when implanted children were compared at the same follow-up moment postoperatively, there was almost a complete overlap in scores. Therefore, studies that compare children at the same time postoperatively are essential. The CDaCI (Childhood Development after Cochlear Implantation) study [Niparko et al., 2010] is one of the few retrieved prospective, longitudinal studies of auditory and language benefits obviating these limitations.

An earlier review marked the limited and lower quality of evidence for age-at-CI effects on PCI performance [Vlastarakos et al., 2010]. We confirm the lack of level 1 evidence but provide additional evidence from more recent studies [Colletti et al., 2012; Leigh et al., 2013; Holman et al., 2013; Dunn et al., 2014] comparing children implanted before the age of 1 year with children implanted between 12 and 24 months on longer follow-up (>48 months). In addition to the review of Vlastarakos et al.
[2010], we assessed receptive language and auditory performance outcome measures.

Due to the recent trend of earlier pediatric implantation, the majority of the children have not yet reached an age in which objective measures can be applied. In addition, elected subjective measures might be too grammatically complex (e.g. GASP scores) for these young children [Zwolan et al., 2004; Lesinski-Schiedat et al., 2005]. Another consequence of the aforementioned trend is that a limited number of children are implanted early and current study samples might be too small to show significant differences between different age-at-CI groups [Lesinski-Schiedat et al., 2005; Tomblin et al., 2005]. Therefore, there is a need for age-normed test standards for both meaningful comparisons of these young implanted children with $\mathrm{NH}$ peers and comparisons of study results with respect to age at CI. A recent survey [Uhler and Gifford, 2014] proved the lack of consistency in the preoperative and postoperative selection of speech perception measures across pediatric CI centers. The need for uniform protocols to assess children preoperatively and the development of a working group to establish a standard pediatric postoperative test battery (similar to the adult Minimum Speech Test Battery) was underlined [Uhler and Gifford, 2014]. In addition, variability in CI fitting protocols exist: in a worldwide survey [Vaerenberg et al., 2014], the large variability in all aspects of the CI fitting process and the small role that objective measures play in this process were marked.

Some limitations of this review should be mentioned. First, we refrained from including noncomparative studies of patients implanted before the age of 1 year, because the number of comparative studies provided sufficient direct evidence to address our review query. The fact that positive study outcomes might be more likely to be reported (reporting bias) could have influenced our conclusions. In addition, various confounders are known to influence the post-CI performance [Cheng et al., 1999; Zwolan et al., 2004], such as the communication mode (speech only or speech/sign combined) and the intelligence and participation and support of the child's family during the rehabilitation [Suh et al., 2009]. Therefore, there is a need for additional multivariate analysis in studies to accurately assess the effect of age at CI. The majority of studies consisted of retrospective designs with inconsistent or incomplete language measures and lacked multivariate analysis. Therefore, we applied critical appraisal to select the literature that most adequately corrected for these confounders and lack of transparency in data collection. Third, since language is complex behavior consisting of multiple sensitive periods of various speech 
and language skills [Houston and Miyamoto, 2010], it is difficult to assess language as one exact outcome measure. By assessing multiple speech and language outcome measures (tables 2-5), we aimed to assess language development as complete and accurately as possible.

\section{Conclusion}

In conclusion, our systematic review provides consistent evidence for early PCI; however, the literature remains indistinct about the additional benefit of implantation before the age of 12 months. The current best evi- dence showed that early implanted children ( $<12$ months) score better on speech production (DEAP and IT-MAISscores), auditory performance (CAP-II score) and on two out of the five receptive language scores (combined PLS4 and OWLS and PPVT scores) compared to their later implanted peers ( $>12$ months). This evidence consists of cohort studies with a moderate to high RoB; therefore, protocols for standardized preoperative and postoperative evaluations and CI fitting procedures should be developed to allow consistent comparisons of speech and language outcomes between various age-at-CI groups and to gather additional high-level evidence for timely implantation for deaf-born children.

\section{Appendix}

Table A1. Speech and language outcome measures

\begin{tabular}{|c|c|c|}
\hline Outcome measure & Applicable age & Test content \\
\hline \multicolumn{3}{|l|}{ Speech perception } \\
\hline CNC scores & $>3$ years & $\begin{array}{l}\text { A 500-monosyllable word test to assess open-set word recognition [Peterson and Lehiste, 1962] } \\
\text { (no minimal age known; most likely after the age of } 3 \text { years) }\end{array}$ \\
\hline PB-K & $5-7$ years & A monosyllable open-set test to assess spoken word recognition (50 phonetically balanced words) [Dunn et al., 2014] \\
\hline WIPI & $>4$ years & $\begin{array}{l}\text { A } 25 \text {-item, } 6 \text {-choice monosyllable closed-set discrimination task where a child must identify a phonetically similar } \\
\text { word represented by } 1 \text { of the } 6 \text { pictures [Fryauf-Bertschy et al., 1997] }\end{array}$ \\
\hline GASP & $>5$ years & An open-set test which measures the ability to understand simple sentences [Erber, 1982] \\
\hline \multicolumn{3}{|l|}{ Speech production } \\
\hline DEAP & $3-83$ months & Test designed to identify the presence of a delay in articulation or phonology [Dodd et al., 2002] \\
\hline SIR & $>1$ year & Used to rank spontaneous speech production into five hierarchic scales [Cox, 1989] \\
\hline IT-MAIS & Birth to 36 months & $\begin{array}{l}\text { A structured parental-reported scale designed to assess the child's spontaneous responses to sound in its everyday en- } \\
\text { vironment; it assesses (1) vocalization behavior, (2) alerting to sounds and } \\
\text { (3) deriving meaning from sound; scores can be converted to NH age equivalents } \\
\text { [Zimmerman-Phillips et al., 2000] }\end{array}$ \\
\hline MAIS & No limit & Evaluation of observable auditory behavior in everyday situations [Robbins et al., 1991] \\
\hline LittlEARS $^{\circledR}$ & $\begin{array}{l}\text { Until hearing age } \\
\text { of } 24 \text { months }\end{array}$ & $\begin{array}{l}\text { A parental questionnaire to assess the auditory development of their child; normative data are available [Tsiakpini et } \\
\text { al., 2004] }\end{array}$ \\
\hline \multicolumn{3}{|l|}{ Receptive language } \\
\hline OWLS & $\begin{aligned} & 3-21 \text { years } \\
> & 5 \text { years }(\text { written })\end{aligned}$ & $\begin{array}{l}\text { Individually administered language test assessing receptive and expressive language } \\
\text { [Carrow-Woolfolk, 1996] }\end{array}$ \\
\hline $\mathrm{CELF}^{\circledR}$ & $5-21$ years & $\begin{array}{l}\text { An individually administered language test assessing receptive and expressive language; it can determine whether a } \\
\text { language disorder is present; norm-referenced scores are available [Semel et al., 2003] } \\
\text { CELF-3 and CELF-4 yielding correlation (correlation coefficient: 0.37-0.79) [Dunn, 1997] }\end{array}$ \\
\hline PLS & Birth to 83 months & $\begin{array}{l}\text { A standardized test of auditory comprehension and expressive communication for infants and toddlers; age-equiva- } \\
\text { lent scores can be calculated [Zimmerman, 2002] }\end{array}$ \\
\hline PPVT & $>30$ months & $\begin{array}{l}\text { Provides information to compare receptive and expressive vocabulary skills; age/grade equivalents and normal curve } \\
\text { equivalents are provided [Dunn, 1997] } \\
\text { PPVT-3 and PPVT-4 strongly correlated (correlation coefficient }=0.84 \text { ) [Dunn, 1997] }\end{array}$ \\
\hline PPVT-R & $>30$ months & Receptive language level relative to that of NH peers [Dunn, 1997] \\
\hline K-PVT & $>30$ months & Korean version of the PPVT [Kim et al., 1995] \\
\hline RDLS & $1-6$ years & $\begin{array}{l}\text { A norm-referenced test to assess language abilities; it contains two scales: (1) verbal comprehension and (2) expres- } \\
\text { sive language [Edwards et al., 1997] }\end{array}$ \\
\hline MB-CDI & $\begin{array}{l}8-18 \text { months (gestures) } \\
16-30 \text { months (sentences) } \\
>30 \text { months (phrases) }\end{array}$ & $\begin{array}{l}\text { Questionnaire for parents to identify various words that their child either says or signs; norms for hearing children } \\
\text { between } 18 \text { and } 36 \text { months of age are available [Fenson et al., 2006] }\end{array}$ \\
\hline $\begin{array}{l}\text { Auditory performance } \\
\text { CAP }\end{array}$ & Infancy-adulthood & $\begin{array}{l}\text { CAP scores reflect a profile of the developing child and can be used to monitor auditory progress of the child; CAP } \\
\text { ceiling level is reached when a score of } 7 \text { is accomplished [Archbold et al., 1995] } \\
\text { CAP-II assesses two additional new scales: CAP-8 and CAP-9 [Ear Foundation, 2009] }\end{array}$ \\
\hline
\end{tabular}

MB-CDI = MacArthur-Bates Communicative Development Inventories; WIPI = Word Intelligibility by Picture Identification (test). 


\section{Acknowledgments}

We thank B. Kramer, PhD (information specialist in health and medical sciences at Utrecht University Library), for her help in establishing the search terms for this systematic review.

In addition, we would like to thank Prof. Dr. Govaerts, The EarGroup, Deurne, Belgium, for his feedback and suggestions for improvement in this paper.

W.G. receives unrestricted grants from Cochlear, MED-EL and Advanced Bionics.

\section{Disclosure Statement}

None of the authors reports any conflict of interest with any other institution or company.

\section{References}

Akin I, Simşek G, Barmak E: A comparison of the long-term efficacy of cochlear implantation at early and late age (in Turkish). Kulak Burun Boğaz Ihtisas Dergisi 2012;22:123-128.

-Anderson I, Weichbold V, D’Haese PS, et al: Cochlear implantation in children under the age of two - what do the outcomes show us. Int $\mathrm{J}$ Pediatr Otorhinolaryngol 2004;68:425-431.

Archbold S, Lutman ME, Marshall DH: Categories of auditory performance. Ann Otol Rhinol Laryngol Suppl 1995;166:312-314.

-Artières F, Vieu A, Mondain M, et al: Impact of early cochlear implantation on the linguistic development of the deaf child. Otol Neurotol 2009;30:736-742.

- Baumgartner WD, Pok SM, Egelierler B, et al: The role of age in pediatric cochlear implantation. Int J Pediatr Otorhinolaryngol 2002;62:223228.

Beadle EA, McKinley DJ, Nikolopoulos TP, et al: Long-term functional outcomes and academic-occupational status in implanted children after 10-14 years of cochlear implant use. Otol Neurotol 2005;26:1152-1160.

Boons T, Brokx JP, Dhooge I, et al: Predictors of spoken language development following pediatric cochlear implantation. Ear Hear 2012, 33:617-639.

Brackett D, Zara CV: Communication outcomes related to early implantation. Am J Otol 1998; 19:453-460.

Bronstein D: Cochlear implant surgery: how young is too young? ENT Today, August 2012.

Carrow-Woolfolk E: Oral and Written Language Scales: Listening Comprehension and Oral Expression Scales Manual. Circle Pines, American Guidance Service, 1996.

Categories of Auditory Performance (CAP)-II. Nottingham Early Assessment Package. Nottingham, The Ear Foundation, 2009.

Chen X, Liu S, Liu B, et al: The effects of age at cochlear implantation and hearing aid trial on auditory performance of Chinese infants. Acta Otolaryngol 2010;130:263-270.

-Cheng AK, Grant GD, Niparko JK: Meta-analysis of pediatric cochlear implant literature. Ann Otol Rhinol Laryngol 1999; 177(suppl): 124-128.

- Ching TY, Dillon H, Marnane V, et al: Outcomes of early- and late-identified children at 3 years of age: findings from a prospective population-based study. Ear Hear 2013;34:535-552.
Clark GM: The cochlear implant: a search for answers. Cochlear Implants Int 2000;1:1-15

Coene M, Schauwers K, Gillis S, et al: Genetic predisposition and sensory experience in language development: evidence from cochlear implanted children. Lang Cogn Processes 2011;26:1083-1101.

Colletti V, Carner M, Miorelli V, et al: Cochlear implantation at under 12 months: report on 10 patients. Laryngoscope 2005;115:445-449.

Colletti L, Mandalà M, Colletti V: Cochlear implants in children younger than 6 months. Otolaryngol Head Neck Surg 2012;147:139-146.

-Connor CM, Craig HK, Raudenbush SW, et al The age at which young deaf children receive cochlear implants and their vocabulary and speech-production growth: is there an added value for early implantation? Ear Hear 2006; 27:628-644

Cox RM, McDaniel DM: Development of the speech intelligibility rating (SIR) test for hearing aid comparisons. J Speech Hear Res 1989; 32:347-352.

Dettman SJ, Pinder D, Briggs RJ, et al: Communication development in children who receive the cochlear implant younger than 12 months: risks versus benefits. Ear Hear 2007;28:11S$18 \mathrm{~S}$.

Dodd B, Zhu H, Crosbie S, et al: Diagnostic Evaluation of Articulation and Phonology. London, Harcourt, 2002.

Dunn LM, Dunn DM: The Peabody Picture Vocabulary Test, ed 3. San Antonio, Pearson, 1997.

Dunn LM, Dunn DM: The Peabody Picture Vocabulary Test, ed 4. San Antonio, Pearson, 2007.

Dunn CC, Walker EA, Oleson J, et al: Longitudinal speech perception and language performance in pediatric cochlear implant users: the effect of age at implantation. Ear Hear 2014. $35: 148-160$

El-Hakim H, Papsin B, Mount RJ, et al: Vocabulary acquisition rate after pediatric cochlear implantation and the impact of age at implantation. Int J Pediatr Otorhinolaryngol 2001; 59:187-194.

Edwards S, Fletcher Gurman M, et al: The Reynell Developmental Language Scales. III. The University of Reading Edition. Los Angeles, Western Psychological Services, 1997.
Erber NP: Auditory Training. Washington, Alexander Graham Bell Association for the Deaf, 1982.

Fenson L, Marchman VL, Thal DJ, et al: MacArthur-Bates Communicative Development Inventories: User's Guide and Technical Manual, ed 2. Baltimore, Brookes, 2006.

-Fryauf-Bertschy H, Tyler RS, Kelsay DM, et al: Cochlear implant use by prelingually deafened children: the influences of age at implant and length of device use. J Speech Lang Hear Res 1997;40:183-199.

Fulcher A, Purcell AA, Baker E, et al: Listen up: children with early identified hearing loss achieve age-appropriate speech/language outcomes by 3 years-of-age. Int J Pediatr Otorhinolaryngol 2012;76:1785-1794.

-Geers AE: Speech, language, and reading skills after early cochlear implantation. Arch Otolaryngol Head Neck Surg 2004;130:634-638

Gibson WP, Rennie M, Psarros C: Outcome of cochlear implantation and auditory verbal training in terms of speech perception, speech production and language. Adv Otorhinolaryngol 2000;57:250-253.

Govaerts PJ, De Beukelaer C, Daemers K, et al: Outcome of cochlear implantation at different ages from 0 to 6 years. Otol Neurotol 2002; 23:885-890.

Gupta D: A predictive model for outcome of cochlear implantation in children below the age of 5 years: a multivariate analysis in Indian scenario. Indian J Otol 2012;18:129-135.

- Hammes DM, Novak MA, Rotz LA, et al: Early identification and cochlear implantation: critical factors for spoken language development. Ann Otol Rhinol Laryngol Suppl 2002;189:74-78.

Hassanzadeh S, Farhadi M, Daneshi A, et al: The effects of age on auditory speech perception development in cochlear-implanted prelingually deaf children. Otolaryngol Head Neck Surg 2002;126:524-527.

Holman MA, Carlson ML, Driscoll CL, et al: Cochlear implantation in children 12 months of age and younger. Otol Neurotol 2013;34:251-258.

Holt RF, Svirsky MA: An exploratory look at pediatric cochlear implantation: is earliest always best? Ear Hear2008;29:492-511.

-Houston DM, Jusczyk PW: Infants' long-term memory for the sound patterns of words and voices. J Exp Psychol Hum Percept Perform 2003;29:1143-1154.
Is There a Speech and Language

Developmental Benefit? 
Houston DM, Miyamoto RT: Effects of early auditory experience on word learning and speech perception in deaf children with cochlear implants: implications for sensitive periods of language development. Otol Neurotol 2010;31:1248-1253.

Iwasaki S, Nishio S, Moteki H, et al: Language development in Japanese children who receive cochlear implant and/or hearing aid. Int J Pediatr Otorhinolaryngol 2012;76:433-438.

- James D, Rajput K, Brinton J, et al: Phonological awareness, vocabulary, and word reading in children who use cochlear implants: does age of implantation explain individual variability in performance outcomes and growth? J Deaf Stud Deaf Educ 2008;13:117-137.

Kim YT, Chang HS, Im SS, et al: Picture vocabulary test. Seoul, Seoul Community Rehabilitation Center, 1995.

Koopmans-van Beinum FJ, van der Stelt JM: Early Stages in the Development of Speech Movements. Precursors of Early Speech. New York, Stockton, 1986, pp 37-50.

Lammers MJ, Jansen TT, Grolman W, et al: The influence of newborn hearing screening on the age at cochlear implantation in children. Laryngoscope 2015;125:985-990.

- Laszig R, Aschendorff A, Beck R, et al: Langzeitergebnisse nach Kochleaimplantatversorgung bei Kindern. HNO 2009;57:657-662.

Leigh J, Dettman S, Dowell R, et al: Communication development in children who receive a cochlear implant by 12 months of age. Otol Neurotol 2013;34:443-450.

- Lesinski-Schiedat A, Illg A, Warnecke A, et al: Kochleaimplantation bei Kindern im 1. Lebensjahr - vorläufige Ergebnisse. HNO 2005; 54:565-572.

Lonka E, Hasan M, Komulainen E: Spoken language skills and educational placement in Finnish children with cochlear implants. Folia Phoniatr Logop 2011;63:296-304.

Loundon N, Busquet D, Roger G, et al: Audiophonological results after cochlear implantation in 40 congenitally deaf patients: preliminary results. Int J Pediatr Otorhinolaryngol 2000; $56: 9-21$.

Low WK, bin Iskandar MF, Sarepaka GK: Outcome of early cochlear implantation. Ann Acad Med Singapore 2008;37(12 suppl): 49-53.

Mah-rya LA, Yoshinaga-Itano C: Early identification of infants with significant hearing loss and the Minnesota Child Development Inventory. Semin Hear 1995; 16:124139.

Manrique M, Cervera-Paz FJ, Huarte A, et al: Prospective long-term auditory results of cochlear implantation in prelinguistically deafened children: the importance of early implantation. Acta Otolaryngol Suppl 2004;552:55-63.

-May-Mederake B: Early intervention and assessment of speech and language development in young children with cochlear implants. Int J Pediatr Otorhinolaryngol 2012;76:939-946.
McConkey Robbins A, Koch DB, Osberger MJ, et al: Effect of age at cochlear implantation on auditory skill development in infants and toddlers. Arch Otolaryngol Head Neck Surg 2004; 130:570-574.

-Miyamoto RT, Hay-McCutcheon MJ, Kirk KI, et al: Language skills of profoundly deaf children who received cochlear implants under 12 months of age: a preliminary study. Acta Otolaryngol 2008;128:373-377.

Moher D, Liberati A, Tetzlaff J, et al: Preferred reporting items for systematic reviews and meta-analyses: the PRISMA statement. J Clin Epidemiol 2009;62:1006-1012.

Moog JS, Geers AE: Speech and language acquisition in young children after cochlear implantation. Otolaryngol Clin North Am 1999;32: 1127-1141.

Nicholas JG, Geers AE: Will they catch up? The role of age at cochlear implantation in the spoken language development of children with severe to profound hearing loss. J Speech Lang Hear Res 2007;50:1048-1062.

Nicholas JG, Geers AE: Spoken language benefits of extending cochlear implant candidacy below 12 months of age. Otol Neurotol 2013;34: 532-538.

Niparko JK, Tobey EA, Thal DJ, et al: Spoken language development in children following cochlear implantation. JAMA 2010;303:14981506.

Oller DK: Metaphonology and Infant Vocalizations. Precursors of Early Speech. New York, Stockton, 1986, pp 21-36.

Papsin BC, Gysin C, Picton N, et al: Speech perception outcome measures in pre-lingually deaf children up to four years after cochlear implantation. Ann Otol Rhinol Laryngol 2000; 185:38-42.

Peterson GE, Lehiste I: Revised CNC lists for auditory tests. J Speech Hear Disord 1962;27: 62-70.

Rinaldi P, Baruffaldi F, Burdo S, et al: Linguistic and pragmatic skills in toddlers with cochlear implant. Int J Lang Commun Disord 2013;48: 715-725.

Robbins AM, Renshaw JJ, Berry SW: Evaluating meaningful auditory integration in profoundly hearing-impaired children. Am J Otol 1991; 12(suppl):144-150

Semel E, Wigg EH, Secord WA: Clinical Evaluation of Language Fundamentals, ed 4 (CELF4). Toronto, Psychological Corporation/A Harcourt Assessment Company, 2003.

-Schauwers K, Gillis S, Daemers K, et al: Cochlear implantation between 5 and 20 months of age: the onset of babbling and the audiologic outcome. Otol Neurotol 2004;25:263-270.

-Sharma A, Dorman MF, Spahr AJ: A sensitive period for the development of the central auditory system in children with cochlear implants: implications for age at implantation. Ear Hear 2002;23:532-539.

-Sharma A, Gilley PM, Dorman MF, et al: Deprivation-induced cortical reorganization in children with cochlear implants. Int J Audiol 2007;46:494-499.
Suh M-W, Cho EK, Kim BJ, et al: Long term outcomes of early cochlear implantation in Korea. Clin Exp Otorhinolaryngol 2009;2:120125.

Svirsky MA, Teoh SW, Neuburger H: Development of language and speech perception in congenitally, profoundly deaf children as a function of age at implantation. Audiol Neurotol 2004;9:224-233.

-Szagun G, Stumper B: Age or experience? The influence of age at implantation and social and linguistic environment on language development in children with cochlear implants. J Speech Lang Hear Res 2012;55: 1640-1654.

Tait ME, Nikopoulos TP, Lutman ME: Age at implantation and development of vocal and auditory preverbal skills in implanted deaf children. Int J Pediatr Otorhinolaryngol 2007;71: 603-610.

Tajudeen BA, Waltzman SB, Jethanamest D, et al: Speech perception in congenitally deaf children receiving cochlear implants in the first year of life. Otol Neurotol 2010;31:12541260.

Tomblin JB, Barker BA, Spencer LJ, et al: The effect of age at cochlear implant initial stimulation on expressive language growth in infants and toddlers. J Speech Lang Hear Res 2005;48: 853-867.

Tsiakpini L, Weichbold V, Kuehn-Inacker H, et al: LittlEARS ${ }^{\circledR}$ Auditory Questionnaire. Innsbruck, MED-EL, 2004.

Uhler K, Gifford RH: Current trends in pediatric cochlear implant candidate selection and postoperative follow-up. Am J Audiol 2014; 23:309-325.

-Uziel AS, Sillon M, Viea A, et al: Ten-year followup of a consecutive series of children with multichannel cochlear implants. Otol Neurotol 2007;28:615-628.

-Vaerenberg B, Smits C, De Ceulaer G, et al: Cochlear implant programming: a global survey on the state of the art. ScientificWorldJournal 2014;014:501738

-Vlastarakos PV, Proikas K, Papacharalampous G, et al: Cochlear implantation under the first year of age - the outcomes. A critical systematic review and meta-analysis. Int J Pediatr Otorhinolaryngol 2010;74:119-126.

Wang NM, Huang TS, Wu C-W, et al: Pediatric cochlear implantation in Taiwan: long-term communication outcomes. Int J Pediatr Otorhinolaryngol 2007;71:1775-1782.

Zimmerman IL: Preschool Language Scales, ed 4. San Antonio, Psychological Corporation, 2002.

Zimmerman-Phillips S, Robbins AM, Osberger MJ: Assessing cochlear implant benefit in very young children. Ann Otol Rhinol Laryngol Suppl 2000;185:42-43.

Z Zwolan TA, Ashbaugh CM, Alarfaj A, et al: Pediatric cochlear implant patient performance as a function of age at implantation. Otol Neurotol 2004;25:112-120. 